\title{
Synthesis, characterization and antitumor activity of Ln(III) complexes with hydrazone Schiff base derived from 2-acetylpyridine and isonicotinohydrazone
}

\author{
JING XIE $^{1 *}$, SHANSHAN SHEN ${ }^{2 *}$, RUHUA CHEN $^{3 *}, \mathrm{JUN} \mathrm{XU}^{4}, \mathrm{KUN} \mathrm{DONG}^{4}, \mathrm{JIANCUI} \mathrm{HUANG}^{4}$, \\ QIN LU ${ }^{3}$, WENJIAO ZHU ${ }^{5}$, TIELIANG MA ${ }^{5}$, LEI JIA ${ }^{4}$, HONGXIN CAI $^{4}$ and TAOFENG ZHU ${ }^{3}$ \\ ${ }^{1}$ Department of Geriatrics, The Affiliated Yixing Hospital of Jiangsu University, Yixing, Jiangsu 214200; \\ ${ }^{2}$ Department of Gastroenterology, The Affiliated Drum Tower Hospital of Nanjing University, Medical School, \\ Nanjing, Jiangsu 210008; ${ }^{3}$ Department of Respiration, The Affiliated Yixing Hospital of Jiangsu University, \\ Yixing, Jiangsu 214200; ${ }^{4}$ Department of Physics and Chemistry, Henan Polytechnic University, Jiaozuo, Henan 454000; \\ ${ }^{5}$ Central Laboratory, The Affiliated Yixing Hospital of Jiangsu University, Yixing, Jiangsu 214200, P.R. China
}

Received June 8, 2015; Accepted February 27, 2017

DOI: $10.3892 / \mathrm{ol} .2017 .6018$

\begin{abstract}
In the present study, two isostructural lanthanide (Ln) (III) complexes, namely $\left.\mathrm{Ln}(\mathrm{HL})_{2}\left(\mathrm{NO}_{3}\right)\left(\mathrm{CH}_{3} \mathrm{OH}\right)_{2}\right) \cdot \mathrm{CH}_{3} \mathrm{OH}$, where $\mathrm{Ln}=\mathrm{La}$ in complex 1 and $\mathrm{Ce}$ in complex 2 , and hydrogen ligand $(\mathrm{HL})=(\mathrm{E})-\mathrm{N}^{\prime}-[1-(2-$ pyridinyl)ethylidene]isonicotinohydrazone, have been isolated and characterized by elemental analysis, infrared spectra and single-crystal X-ray diffraction analysis. The results revealed that the acylhydrazone ligand HL in each complex was deprotonated as an anionic ligand and coordinated to the central $\mathrm{La}(\mathrm{III})$ ion via enolization of oxygen and nitrogen atoms. Furthermore, the antitumor effects and potential mechanisms of the two complexes were explored in the human lung cancer cell line A549 and in the human gastric cancer cell lines BGC823 and SGC7901. In the present study, the roles the two complexes on the proliferation and apoptosis of the above tumor cell lines were determined by MTT assay and Annexin V/propidium iodide flow cytometry, respectively. Furthermore, various apoptosis-associated key genes, including caspase 3, B cell lymphoma (Bcl)-2associated $\mathrm{X}$ protein (Bax) and Bcl-2, were detected by western blotting to explore the possible antitumor mechanisms of the
\end{abstract}

Correspondence to: Mr. Taofeng Zhu, Department of Respiratory, The Affiliated Yixing Hospital of Jiangsu University, 75 Tongzhenguan Road, Yixing, Jiangsu 214200, P.R. China

E-mail: taofengzhu@foxmail.com

Professor Hongxin Cai, Department of Physics and Chemistry, Henan Polytechnic University, 2001 Shiji Street, Jiaozuo, Henan 454000, P.R. China

E-mail: me2001@hpu.edu.cn

${ }^{*}$ Contributed equally

Key words: Ln(III) complex, acylhydrazone, isonicotinohydrazone, antitumor activity, apoptosis two complexes. The results revealed that the two complexes had comparable antitumor activities in terms of inhibiting proliferation and inducing apoptosis in tumor cell lines. The changes in the protein expression levels of caspase 3, Bax and $\mathrm{Bcl}-2$ further verified the apoptosis-promoting mechanisms of the two complexes in tumor cell lines. These findings have a great potential in biomedical applications of novel $\mathrm{Ln}(\mathrm{III})$ complexes.

\section{Introduction}

It is well known that Schiff bases are important in the development of coordination chemistry due to their ease of synthesis and structural tenability, and their ability to form a wide variety of complexes of chemical, biological and industrial importance (1-5). Aroyl hydrazones are members of the Schiff bases family, which are built with aromatic acid hydrazides (aroyl hydrazides) and carbonyl compounds (1). Hydrazone complexes have been studied for numerous years due to their antimicrobial and antitumor activities (6-11). Hydrazone ligands can offer a combination of amide oxygen and imine nitrogen as donor atoms, with the imine nitrogen being involved in the formation of an N-N bond reminiscent of a doubly reduced azo functionality. Due to the short N-N bond length, the hydrazone ligands act mostly as tridentate moieties, although they have the potential to behave as bridging tetradentate ligands (12).

The chemistry of the trivalent lanthanide (Ln) ions has attracted significant attention in the last 40 years (13-15). In addition to their magnetic and photophysical properties, the bioactivities of Lns, including their antimicrobial, antitumor, antivirus and anticoagulant action, as well as their ability to prevent arteriosclerosis, have been explored in recent decades (16-19).

The present study synthesized the hydrogen ligand (HL) (E)-N'-[1-(2-pyridinyl)ethylidene]isonicotinohydrazone and prepared its two Ln(III) complexes. Furthermore, the antitumor effects and potential mechanisms of the two $\mathrm{Ln}$ (III) complexes with HL were explored in the human lung cancer cell line A549 and in the human gastric cancer cell lines BGC823 and SGC7901. 
Table I. Crystal data and structure refinement for complexes 1 and 2.

\begin{tabular}{|c|c|c|}
\hline Characteristics $^{\mathrm{a}}$ & Complex 1 & Complex 2 \\
\hline Empirical formula & $\mathrm{C}_{29} \mathrm{H}_{34} \mathrm{~N}_{9} \mathrm{O}_{8} \mathrm{La}$ & $\mathrm{C}_{29} \mathrm{H}_{34} \mathrm{~N}_{9} \mathrm{O}_{8} \mathrm{Ce}$ \\
\hline Molecular weight, Da & 775.56 & 776.77 \\
\hline Temperature, $\mathrm{K}$ & $296(2)$ & $296(2)$ \\
\hline Wavelength, nm & 0.071073 & 0.071073 \\
\hline Crystal system & Monoclinic & Monoclinic \\
\hline Space group & Pn & Pn \\
\hline $\mathrm{Z}$ & 4 & 4 \\
\hline$a, \mathrm{~nm}$ & $1.15714(6)$ & $1.16586(6)$ \\
\hline$b, \mathrm{~nm}$ & $1.13776(6)$ & $1.14190(6)$ \\
\hline$c, \mathrm{~nm}$ & $1.30471(7)$ & $1.29827(7)$ \\
\hline$\beta,^{\circ}$ & $99.4880(10)$ & $100.0540(10)$ \\
\hline$V, \mathrm{~nm}^{3}$ & $1.69421(15)$ & $1.70184(16)$ \\
\hline $\mathrm{D}_{\text {calc }}, \mathrm{g} / \mathrm{cm}^{3}$ & 1.520 & 1.516 \\
\hline$\mu, \mathrm{mm}^{-1}$ & 1.321 & 1.397 \\
\hline $\mathrm{F}(000)$ & 784 & 786 \\
\hline Crystal size, $\mathrm{mm}$ & $0.20 \times 0.18 \times 0.16$ & $0.22 \times 0.15 \times 0.14$ \\
\hline$\theta$ range for data collection, ${ }^{\circ}$ & $2.18-25.00$ & $1.78-25.00$ \\
\hline Reflections collected & 8,446 & 8,517 \\
\hline Independent reflections, $\mathrm{R}_{\mathrm{int}}$ & $4,956(0.0153)$ & $4,547(0.0170)$ \\
\hline Final GooF & 1.060 & 1.091 \\
\hline$R_{1}, w R_{2}[\mathrm{I}>2 \sigma(\mathrm{I})]$ & $R_{1}=0.0305, w R_{2}=0.0805$ & $R_{1}=0.0300, w R_{2}=0.0871$ \\
\hline$R_{1}, w R_{2}$ (all data) & $R_{1}=0.0323, w R_{2}=0.0830$ & $R_{1}=0.0329, w R_{2}=0.0901$ \\
\hline
\end{tabular}

${ }^{a}$ Temperature, $a, b, c, \beta, \mathrm{V}$ and independent reflections values are provided as mean(standard deviation). Z, cell formula units; $a, b$ and $c$, cell length; $\beta$, cell angle; $\mathrm{V}$, cell volume; $\mathrm{D}_{\text {calc }}$, crystal density; $\mu$, absorption coefficient; $\mathrm{F}(000)$, electronic number of a single crystal; $\mathrm{R}_{\text {int }}$, independent reflections; GooF, goodness of fit; $R_{1}$, value of all diffraction points; $w R_{2}$, value of the observable diffraction points.

\section{Materials and methods}

Materials and measurements. All starting materials were obtained commercially and used as received. All the rear earth salts were purchased from Beijing Chemical Works (Beijing, China). The A549 human lung cancer, and the BGC823 and SGC7901 human gastric cancer cell lines, were obtained from the Cell Culture Center of the Basic Institute of Medical Sciences, Peking Union Medical College (Beijing, China). Cell culture reagents were purchased from Gibco (Thermo Fisher Scientific, Inc., Waltham, MA, USA). MTT and dimethyl sulfoxide (DMSO) were purchased from Sigma-Aldrich (Merck KGaA, Darmstadt, Germany). Polyvinylidene fluoride (PVDF) membranes and non-fat dry milk were obtained from EMD Millipore (Billerica, MA, USA).

The elemental analyses were performed in the microanalytical laboratory of the Department of Chemistry, Lanzhou University (Lanzhou, China). The infrared (IR) spectra (KBr pellet) were recorded using an FTS 165 Fourier transform (FT)-IR spectrophotometer (Bio-Rad Laboratories, Inc., Hercules, CA, USA) in the range of $4,000-400 \mathrm{~cm}^{-1}$. Cell lines were cultured in an incubator (Thermo Fisher Scientific, Inc.) under the condition of $100 \%$ humidity, $5 \% \mathrm{CO}_{2}$ at $37^{\circ} \mathrm{C}$. RPMI-1640 culture medium was purchased from HycClone (GE Healthcare Life Sciences, Chalfont, UK). CKX51 microscope (Olympus Corporation,
Tokyo, Japan) and ToupCam FMA050 (ToupTek Photonics, Hangzhou, China) were used to obtain images of the cells. The MTT assay was performed using a microplate reader (Infinite F50; Tecan Schweiz AG, Männedorf, Switzerland). The flow cytometer Accuri C6 was purchased from BD Biosciences (Franklin Lakes, NJ, USA).

Preparations of the ligand and complexes. The ligand HL was prepared as described previously (20). In brief, HL was obtained by condensation of 2-acetylpyridine $(0.1 \mathrm{mmol})$ and isonicotinohydrazone $(0.1 \mathrm{mmol})$ in ethanol solution with the addition of $0.1 \mathrm{ml}$ concentrated acetic acid. The parameters of the IR spectrum of HL were as follows: IR $(\mathrm{KBr}) \mathrm{cm}^{-1}$ : $v(\mathrm{NH}), 3,194 ; v(\mathrm{C}=\mathrm{O}), 1,679$; and $v(\mathrm{C}=\mathrm{N}), 1,586$. Complex 1 was prepared as follows: $\mathrm{Ce}\left(\mathrm{NO}_{3}\right)_{3} \cdot 6 \mathrm{H}_{2} \mathrm{O}(217.1 \mathrm{mg}, 0.5 \mathrm{mmol}$; Beijing Chemical Works) in ethanol $(20 \mathrm{ml})$ was added to a solution containing the ligand HL $(240 \mathrm{mg}, 1 \mathrm{mmol})$ in methanol $(10 \mathrm{ml})$ with $0.05 \mathrm{ml}$ triethylamine. The mixture was stirred for $12 \mathrm{~h}$ at $25^{\circ} \mathrm{C}$ to allow the formation of the precipitate of the $\mathrm{Ce}$ (III) complex. The precipitate was separated by centrifugation at $2,000 \times \mathrm{g}$ for $10 \mathrm{~min}$ at $25^{\circ} \mathrm{C}$, and washed three times with ethanol and one time with ether, and finally dried in vacuo. Slow evaporation of the mixed methanol/ ethanol solution containing Ce(III) complex 1 led to a yellow single crystal that was suitable for X-ray diffraction (XRD). The calculated parameters for $\mathrm{C}_{29} \mathrm{H}_{34} \mathrm{CeN}_{9} \mathrm{O}_{8}$ were as follows: 
C, 44.84; H, 4.41; and N, 16.23. The determined parameters for $\mathrm{C}_{29} \mathrm{H}_{34} \mathrm{CeN}_{9} \mathrm{O}_{8}$ were as follows: $\mathrm{C}, 44.51 ; \mathrm{H}, 4.82$; and $\mathrm{N}, 15.98$. IR $(\mathrm{KBr}) \mathrm{cm}^{-1}: v(\mathrm{NH}), 3,074 ; v(\mathrm{C}=\mathrm{O}), 1,586$; and $v(\mathrm{C}=\mathrm{N})$, 1,519. The La(III) complex 2 was synthesized as described earlier. The calculated parameters for $\mathrm{C}_{28} \mathrm{H}_{34} \mathrm{LaN}_{9} \mathrm{O}_{9}$ were as follows: C, 43.14; H, 4.40; and N, 16.17, while the measured parameters where as follows: $\mathrm{C}, 43.35 ; \mathrm{H}, 4.77$; and $\mathrm{N}, 15.98$. IR $(\mathrm{KBr}) \mathrm{cm}^{-1}: v(\mathrm{NH}), 3,081 ; v(\mathrm{C}=\mathrm{O}), 1,578$; and $v(\mathrm{C}=\mathrm{N})$, 1,518. The complexes are soluble at room temperature in ethanol, methanol, dimethylformamide and DMSO.

$X$-ray crystallography. The XRD measurements for the two complexes were performed on a SMART APEX II CCD diffractometer (Bruker Corporation, Billerica, MA, USA) equipped with a graphite monochromatized Mo-Ka radiation $(\lambda=0.071073 \mathrm{~nm})$ by using $\phi-\omega$ scan mode. Mo-Ka radiation is the standard operation used in structure elucidation, where Mo-Ka indicates the molybdenum-kalium target radiography and $\lambda$ is the $\mathrm{X}$-Ray diffraction wavelength. Semi-empirical absorption correction was applied to the intensity data using the SADABS program version 2.03 (Bruker Corporation) (21). The structures were solved by direct methods and refined by full matrix least-square on $F^{2}$ using the SHELXTL version 97 program (Bruker Corporation) (22). The non-hydrogen atoms of the disordered methanol solvent molecules were refined isotropically. However, the $\mathrm{H}$ atoms on the solvent molecules were not added, and were directly included in the molecular formula. The other non-hydrogen atoms were refined anisotropically. $\mathrm{H}$ atoms for coordinated solvent molecules were located from difference Fourier maps and refined with restraints in bond length and thermal parameters. All the other $\mathrm{H}$ atoms were positioned geometrically and refined using a riding model. Details of the crystal parameters, data collection and refinements for complexes 1 and 2 are summarized in Table I. The selected bond lengths and angles are listed in Tables II and III, respectively.

Cytotoxic activity assay. The effects of the DMSO-soluble HL and the complexes 1 and 2 on the proliferation of the human lung cancer cell line A549 and the human gastric cancer lines BGC823 and SGC7901 were explored by MTT assay. The half maximal inhibitory concentration $\left(\mathrm{IC}_{50}\right)$ was further calculated according to the results of the MTT assay. Briefly, the three types of tumor cell lines evaluated in the present study were plated in 96-well plates in triplicate and grown to $75 \%$ confluence. Following treatment with different concentrations of the complexes 1 and 2 for $72 \mathrm{~h}$, the media were replaced with $10 \mu \mathrm{l}$ of fresh medium containing $0.45 \mathrm{mg} / \mathrm{ml}$ MTT reagent. The cells were incubated for $1 \mathrm{~h}$ at $37^{\circ} \mathrm{C}$ in the presence of $5 \% \mathrm{CO}_{2}$ to allow the formation of formazan crystals. The formazan crystals were dissolved by addition of $100 \mu \mathrm{l}$ DMSO during a 4-h incubation period at $37^{\circ} \mathrm{C}$ and $5 \% \mathrm{CO}_{2}$. The colorimetric change was measured on a spectrophotometer at an absorbance wavelength of $570 \mathrm{~nm}$. Data were expressed as the percentage of viability relative to vehicle. At least three independent experiments were performed.

Flow cytometry analysis. Apoptotic rates were determined by flow cytometry using the FITC Annexin V Apoptosis Detection kit I, which contains propidum iodide (PI) for red
Table II. Selected bond lengths in the complexes.

A, Complex 1

\begin{tabular}{ll}
\hline Bond & Length $^{\mathrm{a}}, \mathrm{nm}$ \\
\hline La1-O1 & $0.2463(7)$ \\
La1-O6 & $0.2628(7)$ \\
La1-O3 & $0.2692(10)$ \\
La1-N2 & $0.2809(5)$ \\
La1-O2 & $0.2465(7)$ \\
La1-O7 & $0.2561(8)$ \\
La1-N1 & $0.2786(6)$ \\
La1-N6 & $0.2671(7)$ \\
La1-O4 & $0.2633(8)$ \\
La1-N5 & $0.2693(3)$ \\
\hline
\end{tabular}

B, Complex 2

\begin{tabular}{ll}
\hline Bond & Length $^{\mathrm{a}}, \AA$ \\
\hline Ce1-O2 & $0.2430(9)$ \\
Ce1-O6 & $0.2583(9)$ \\
Ce1-N6 & $0.2676(7)$ \\
Ce1-N2 & $0.2788(5)$ \\
Ce1-O1 & $0.2433(7)$ \\
Ce1-O4 & $0.2623(11)$ \\
Ce1-N5 & $0.2685(3)$ \\
Ce1-O7 & $0.2573(9)$ \\
Ce1-O3 & $0.2661(11)$ \\
Ce1-N1 & $0.2761(5)$ \\
\hline
\end{tabular}

${ }^{a}$ The numbers between parentheses indicate the standard deviation to the third decimal place.

fluorescence detection (cat. no. 556547; BD Biosciences). Briefly, the cancer cells (A549) were seeded at a density of $1 \times 10^{6}$ cells/well in 6-well plates overnight, and then treated with 5, 10 and $15 \mu \mathrm{mol} / 1$ complex 2 for $48 \mathrm{~h}$. Cells $\left(1 \times 10^{6}\right)$ were collected by centrifugation $200 \mathrm{x}$ g for $5 \mathrm{~min}$ at $4^{\circ} \mathrm{C}$ and washed twice with cold PBS. Staining was performed according to the manufacturer's protocol, and the cells were analyzed using a flow cytometer (Accuri C6; BD Biosciences) with $488 \mathrm{~nm}$ excitation wavelength and $530 \mathrm{~nm}$ emission wavelength. The green fluorescence of Annexin $\mathrm{V}$ and the red fluorescence of PI was detected by flow cytometry. The results were analyzed using Cell Quest software version 6.0 (BD Biosciences). At least three independent experiments were performed.

Western blotting. The aforementioned three types of tumor cells were seeded in 6-well plates overnight. Cells were treated with $5 \mu \mathrm{mol} / 1$ complex 2 for $48 \mathrm{~h}$. Upon treatment, all the cell samples were washed twice with PBS and lysed in RIPA Lysis Buffer (cat. no. P0013C; Beyotime Institute of Biotechnology, Haimen, China). The protein concentration of each sample was determined with a bicinchoninic acid assay kit (cat. no. P0009; Beyotime Institute of Biotechnology). The 
Table III. Selected bond angles in the complexes.

\begin{tabular}{|c|c|}
\hline Angle & Size $^{\mathrm{a}}, \stackrel{ }{\circ}$ \\
\hline O1-La1-O2 & $147.8(2)$ \\
\hline O1-La1-O6 & $70.2(2)$ \\
\hline O1-La1-O4 & $85.0(3)$ \\
\hline O6-La1-O4 & $140.8(3)$ \\
\hline O7-La1-N6 & $119.4(2)$ \\
\hline O1-La1-O3 & 131.3(3) \\
\hline O6-La1-O3 & $135.6(3)$ \\
\hline O1-La1-N5 & $73.9(2)$ \\
\hline O6-La1-N5 & $72.4(5)$ \\
\hline O3-La1-N5 & $78.0(2)$ \\
\hline O7-La1-N1 & $75.0(2)$ \\
\hline N6-La1-N1 & $117.8(2)$ \\
\hline O1-La1-N2 & $58.1(2)$ \\
\hline O1-La1-O7 & $81.9(2)$ \\
\hline O2-La1-O6 & $84.0(2)$ \\
\hline O2-La1-O4 & $126.8(3)$ \\
\hline O1-La1-N6 & $123.7(2)$ \\
\hline O6-La1-N6 & $69.2(2)$ \\
\hline O2-La1-O3 & $80.7(3)$ \\
\hline O4-La1-O3 & $48.2(2)$ \\
\hline O2-La1-N5 & $116.8(5)$ \\
\hline O4-La1-N5 & $71.7(2)$ \\
\hline O1-La1-N1 & $118.0(2)$ \\
\hline O6-La1-N1 & $144.6(2)$ \\
\hline O3-La1-N1 & $67.6(2)$ \\
\hline O2-La1-N2 & $125.8(2)$ \\
\hline O4-La1-N2 & $65.9(2)$ \\
\hline N5-La1-N2 & $116.8(2)$ \\
\hline O2-La1-O7 & $72.0(2)$ \\
\hline O7-La1-O6 & $72.2(2)$ \\
\hline O7-La1-O4 & $135.0(3)$ \\
\hline O2-La1-N6 & $59.2(2)$ \\
\hline O4-La1-N6 & $103.6(2)$ \\
\hline O7-La1-O3 & $138.6(3)$ \\
\hline N6-La1-O3 & $67.1(3)$ \\
\hline O7-La1-N5 & $142.2(3)$ \\
\hline N6-La1-N5 & $57.6(4)$ \\
\hline O2-La1-N1 & $73.4(2)$ \\
\hline O4-La1-N1 & $73.8(2)$ \\
\hline N5-La1-N1 & $142.2(4)$ \\
\hline O7-La1-N2 & $70.6(2)$ \\
\hline N6-La1-N2 & $169.5(2)$ \\
\hline N1-La1-N2 & $59.9(2)$ \\
\hline
\end{tabular}

B, Complex 2

\begin{tabular}{lr}
\hline Angle & \multicolumn{1}{c}{ Size $^{\mathrm{a}}{ }^{\circ}$} \\
\hline O2-Ce1-O1 & $147.5(2)$ \\
O2-Ce1-O6 & $83.3(3)$ \\
O2-Ce1-O4 & $128.5(3)$ \\
O6-Ce1-O4 & $140.2(3)$
\end{tabular}

Table III. Continued.

\begin{tabular}{|c|c|}
\hline Angle & Size $^{\mathrm{a}}, \stackrel{ }{\circ}$ \\
\hline O7-Ce1-O3 & $140.3(3)$ \\
\hline O2-Ce1-N6 & $60.1(2)$ \\
\hline O6-Ce1-N6 & $69.2(2)$ \\
\hline O2-Ce1-N5 & $118.1(2)$ \\
\hline O6-Ce1-N5 & $72.9(2)$ \\
\hline N6-Ce1-N5 & $58.1(2)$ \\
\hline O7-Ce1-N1 & $74.9(2)$ \\
\hline O3-Ce1-N1 & $68.7(2)$ \\
\hline $\mathrm{O} 2-\mathrm{Ce} 1-\mathrm{N} 2$ & $125.9(2)$ \\
\hline O6-Ce1-N2 & $119.4(2)$ \\
\hline N6-Ce1-N2 & $168.6(2)$ \\
\hline O2-Ce1-O7 & $71.8(3)$ \\
\hline O1-Ce1-O6 & $70.8(3)$ \\
\hline O1-Ce1-O4 & $83.5(3)$ \\
\hline $\mathrm{O} 2-\mathrm{Ce} 1-\mathrm{O} 3$ & $83.0(3)$ \\
\hline O6-Ce1-O3 & $134.6(3)$ \\
\hline O1-Ce1-N6 & $123.5(2)$ \\
\hline O4-Ce1-N6 & $103.6(3)$ \\
\hline O1-Ce1-N5 & $73.1(2)$ \\
\hline O4-Ce1-N5 & $70.8(2)$ \\
\hline O2-Ce1-N1 & $73.7(2)$ \\
\hline O6-Ce1-N1 & $145.2(2)$ \\
\hline N6-Ce1-N1 & $117.7(2)$ \\
\hline O1-Ce1-N2 & $57.8(2)$ \\
\hline O4-Ce1-N2 & $65.1(3)$ \\
\hline N5-Ce1-N2 & $115.5(3)$ \\
\hline O1-Ce1-O7 & $82.1(3)$ \\
\hline O7-Ce1-O6 & $73.3(3)$ \\
\hline O7-Ce1-O4 & $133.7(3)$ \\
\hline O1-Ce1-O3 & 129.1(3) \\
\hline O4-Ce1-O3 & 48.1(2) \\
\hline O7-Ce1-N6 & $121.0(2)$ \\
\hline O3-Ce1-N6 & $66.4(2)$ \\
\hline O7-Ce1-N5 & $143.1(2)$ \\
\hline O3-Ce1-N5 & $76.1(2)$ \\
\hline O1-Ce1-N1 & $118.0(2)$ \\
\hline O4-Ce1-N1 & $73.8(2)$ \\
\hline N5-Ce1-N1 & $141.2(2)$ \\
\hline O7-Ce1-N2 & $70.0(2)$ \\
\hline N1-Ce1-N2 & $60.3(2)$ \\
\hline O3-Ce1-N2 & $103.6(2)$ \\
\hline
\end{tabular}

samples were separated by $12 \%$ SDS-PAGE, transferred to PVDF membranes by electroblotting and blocked using 5\% dried skimmed milk overnight at $4^{\circ} \mathrm{C}$. Next, the membranes were probed with polyclonal antibodies against caspase 3 (1:1,000; cat. no. 3004; BioVision, Inc., Milpitas, CA, USA), the apoptosis regulators $\mathrm{B}$ cell lymphoma $(\mathrm{Bcl})$-2-associated $\mathrm{X}$ protein (Bax) (1:1,000; cat. no. 3032; BioVision, Inc.) and 
Bcl-2 (1:1,000; cat. no. 3195; BioVision, Inc.) and GAPDH (1:2,000; cat. no. E7EUT5; Abmart, Inc., Shanghai, China) diluted in 5\% bovine serum albumin (cat. no. 10711454001; Roche Applied Science, Penzberg, Germany). The membranes were next incubated for $2 \mathrm{~h}$ at room temperature with secondary alkaline phosphatase (AP)-conjugated anti-mouse immunoglobulin (Ig)G (cat. no. A0258; Beyotime Institute of Biotechnology) and AP-conjugated anti-rabbit IgG (cat. no. A0239; Beyotime Institute of Biotechnology) antibodies, which were diluted 1:1,000 in PBS, followed by incubation with an enhanced chemiluminescent reagent (Lumi-Phos ${ }^{\mathrm{TM}}$ WB Chemiluminescent Substrate; Thermo Fisher Scientific, Inc.) and visualization on an autoradiography film. Membranes were scanned using an ScanJet G4010 Photo Scanner (HP, Inc., Palo Alto, CA, USA) Densitometry values were determined using UN-SCAN-IT version 6.0 software (Silk Scientific, Inc., Orem, UT, USA).

Statistical analysis. All data were analyzed by SAS 6.12 software, and the results were expressed as the mean + standard deviation. To compare the differences between the groups, the statistical significance was analyzed using a one-way analysis of variance followed by post hoc comparisons. $\mathrm{P}<0.05$ was considered to indicate a statistically significant difference.

\section{Results and Discussion}

Crystal structures of complexes 1 and 2. As revealed by single-crystal XRD, complexes 1 and 2 are isostructural and crystallize in the monoclinic $P$ n space group (Table I). The structure of complex 1 will be discussed in detail as a representative example. As shown in Fig. 1A, once coordinated with a metal ion, the acylhydrazone ligand is deprotonated and acts as tridentate mono-basic ligand. The 10 -coordinated La(III) ion with bicapped square antiprism coordination geometry (Fig. 1B) is surrounded by two Lanions with $\mathrm{N}_{2} \mathrm{O}$ donor sets, one bidentate nitrate anion and two methanol molecules. The Ln-O $(\mathrm{N})$ bond lengths are in the range of $0.2463(7)$ to $0.2809(5) \mathrm{nm}$ in complex 1 , slightly longer than those in complex $2[0.2430(9)-0.2788(5) \mathrm{nm}]$ and the reported complex $\left[\mathrm{Pr}(\mathrm{L})_{2}\left(\mathrm{NO}_{3}\right)\left(\mathrm{CH}_{3} \mathrm{OH}\right)_{2}\right] \cdot \mathrm{CH}_{3} \mathrm{CH}_{2} \mathrm{OH}$ [0.2414(2)-0.2707(2) nm] (20), which is probably due to the Ln contraction. The numbers between parentheses in the above lenghts indicate the standard deviation of the bond distances to the third decimal place. In the crystal structure of complex 1, intramolecular $\mathrm{O}-\mathrm{H} \cdots \mathrm{N}$ hydrogen bonds [O6-H6A $\cdots \mathrm{N} 4{ }^{\mathrm{i}}$ and $\mathrm{O} 7-\mathrm{H} 7 \cdots \mathrm{N} 8^{\mathrm{ii}}$, with $D \cdots A$ distances of $0.267(4)$ and $0.2752(8) \mathrm{nm}$, and $D-\mathrm{H} \cdots A$ angles of 142.9 and $163.2^{\circ}$, respectively] link the complex molecules into a chain-like structure (Fig. 1C). This is similar in the crystal structure of complex 2, with $D \cdots A$ distances of $0.272(5)$ and $0.2719(9) \mathrm{nm}$, and $D-\mathrm{H} \cdots A$ angles of 142.1 and $165.9^{\circ}$, respectively.

IR spectra. The solid-state FT-IR spectra of the complexes, recorded on a FT-IR spectrophotometer in the range 4,000-200 $\mathrm{cm}^{-1}$, were fully consistent with their single crystal structures. The samples were studied as powder dispersed in $\mathrm{KBr}$ pellets. The spectral region for all the complexes was somewhat similar due to the similarity in the coordination
A

B
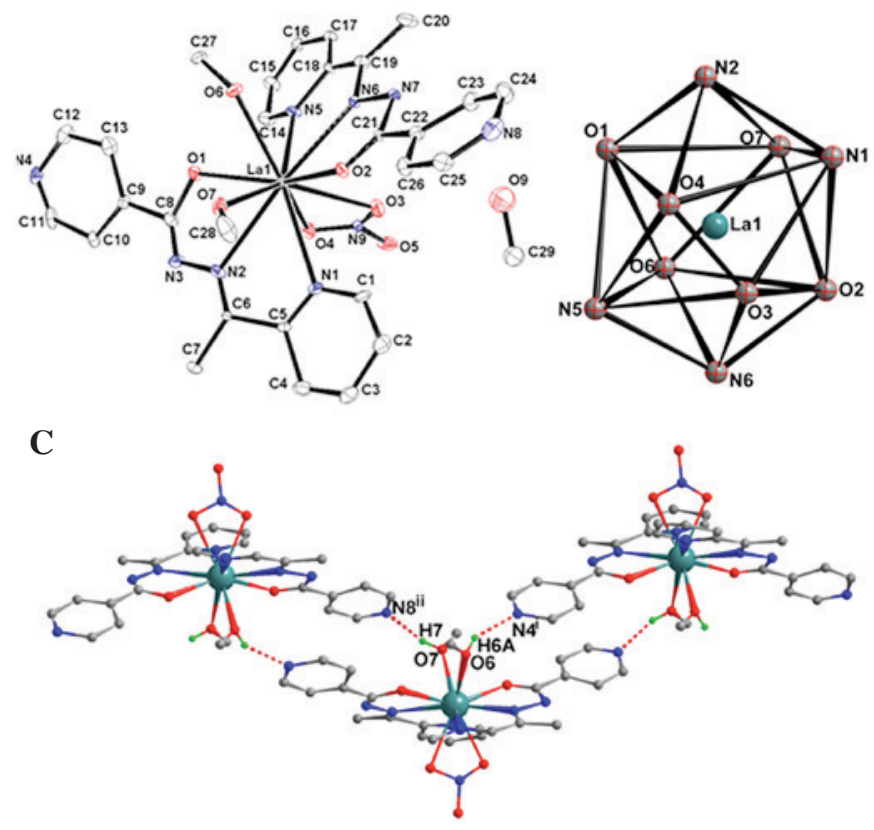

Figure 1. (A) Molecular structure of complex 1 shown with $30 \%$ probability pf displacement ellipsoids ( $\mathrm{H}$ atoms are omitted for clarity). (B) Coordination geometries of the center La ion. (C) Intramolecular hydrogen bonds of extended chain-like structure $(\mathrm{C}-\mathrm{H}$ hydrogen atoms and solvent molecules are omitted for clarity). Symmetry codes: i) -x,y,-z+1/2; and ii) $-\mathrm{x}, \mathrm{y},-\mathrm{z}+1 / 2$.

Table IV. $\mathrm{IC}_{50}(\mu \mathrm{mol} / \mathrm{l})$ values of the ligand and complexes 1 and 2 against the human lung cancer A549 and the human gastric cancer BGC823 and SGC7901 cell lines after incubation for $72 \mathrm{~h}$.

\begin{tabular}{lccc}
\hline & \multicolumn{3}{c}{$\mathrm{IC}_{50}(\mu \mathrm{mol} / \mathrm{l})$} \\
\cline { 2 - 4 } Tested compounds & $\mathrm{A} 549$ & $\mathrm{BGC823}$ & $\mathrm{SGC7901}$ \\
\hline $\mathrm{Ce}\left(\mathrm{NO}_{3}\right)_{3} \cdot 6 \mathrm{H}_{2} \mathrm{O}$ & $>150.0$ & $>150.0$ & $>150.0$ \\
$\mathrm{La}\left(\mathrm{NO}_{3}\right)_{3} \cdot 6 \mathrm{H}_{2} \mathrm{O}$ & $>150.0$ & $>150.0$ & $>150.0$ \\
Ligand & 41.8 & 39.2 & 43.5 \\
Complex 1 & 11.5 & 13.3 & 15.6 \\
Complex 2 & 10.9 & 12.6 & 14.8 \\
\hline
\end{tabular}

$\mathrm{IC}_{50}$, half maximal inhibitory concentration.

modes of the ligands with the metal centre. The $v(C=O)$ of the free ligand is $1,679 \mathrm{~cm}^{-1}$, while for complexes 1 and 2, this peak shifted to 1,586 and $1,578 \mathrm{~cm}^{-1}$, respectively. In addition, the $v$ (ligand-complexes) is $\sim 100 \mathrm{~cm}^{-1}$, thus indicating that the $\mathrm{O}$ atom of the $\mathrm{C}=\mathrm{O}$ bond participates in the coordination to the metal ion. The stretching frequency of the azomethine $(\mathrm{CH}=\mathrm{N})$ group in the hydrazone ligand was observed to be $\sim 1,586 \mathrm{~cm}^{-1}$, which shifted to lower frequency values upon complexation with the metal by $70 \mathrm{~cm}^{-1}$, indicating that the $\mathrm{N}$ atom of the $\mathrm{C}=\mathrm{N}$ bond participates in the coordination to the metal ion. The vibrations $v(\mathrm{~N}-\mathrm{H})$ disappear in the spectra of the two complexes, indicating that the ligand is deprotonated. The new bands at $\sim 550 \mathrm{~cm}^{-1}$ for complexes 1 and 2 are 


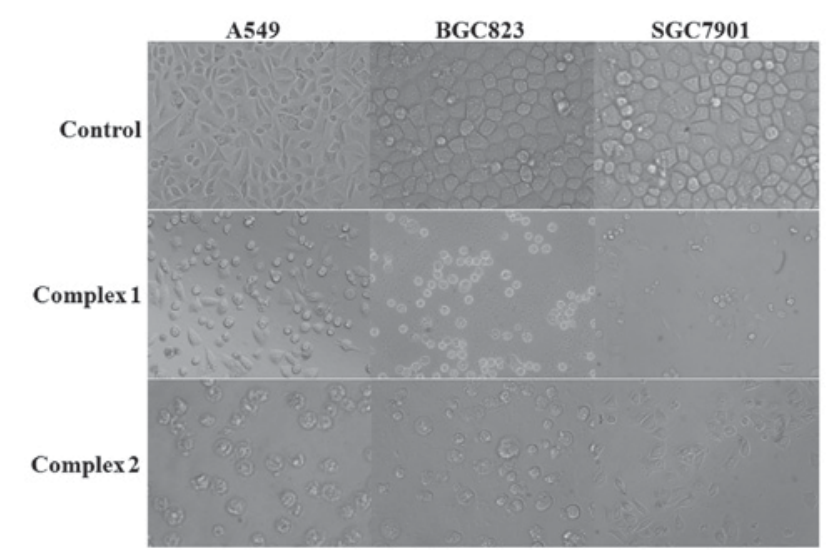

Figure 2. Phase-contrast micrographs of cells treated with complexes 1 and 2. Magnification, $\mathrm{x} 200$.

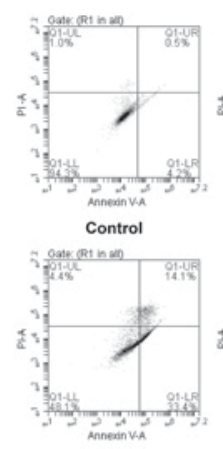

$10 \mu \mathrm{M}$

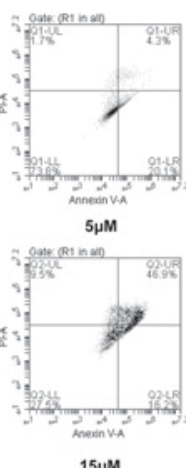

$15 \mu \mathrm{M}$

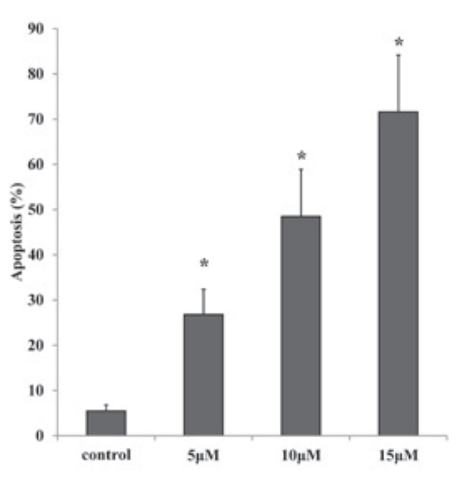

Figure 3. Cells that were stained by Annexin V/PI after treatment with different concentrations of complex 2 for $48 \mathrm{~h}$ and control cells were subjected to flow cytometric measurement to quantify the percentages of apoptosis. The $\mathrm{x}$ axis represents Annexin V-green fluorescent signal and the y axis represents PI-red fluorescent signal. ${ }^{*} \mathrm{P}<0.05$. PI, propidium iodide.

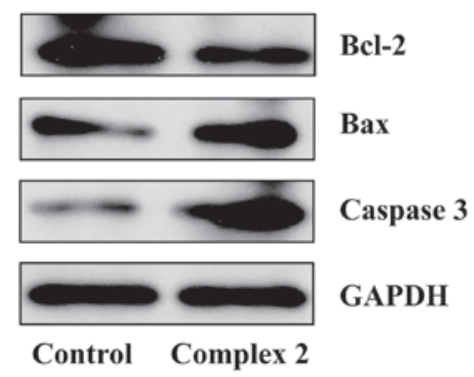

Figure 4. Western blot analysis of the expression levels of caspase 3, Bax and Bcl-2 proteins in A549 lung adenocarcinoma cells following treatment with complex 2. Bcl, B cell lymphoma; Bax, Bcl-2-associated X protein.

assigned to $v(\mathrm{M}-\mathrm{O})$, and the weak peaks at $\sim 470 \mathrm{~cm}^{-1}$ are assigned to $v(\mathrm{M}-\mathrm{N})$.

Antitumor activities. It has been reported that arylhydrazone and their metal complexes display particularly effective antitumor activities, possibly due to their NO bidentate systems (23). In consequence, in vitro cytotoxicity assays were explored in the human lung cancercell line A549 and in the human gastric cancer cell lines BGC823 and SGC7901. The two metal complexes displayed a concentration-dependent cytotoxic profile in all cell lines, and their $\mathrm{IC}_{50}$ values are shown in Table IV. The $\mathrm{IC}_{50}$ values of complexes 1 and 2 were significantly lower than that of the metal-free ligand in all the tested cell lines, which suggested that the coordinated $\mathrm{Ln}(\mathrm{III})$ ion served a major role in mediating the potency of the complexes. Morphological examinations also revealed that the proliferation of the cells was significantly inhibited, and that the cells exhibited morphological changes such as cell shrinkage and detachment (Fig. 2).

Cell apoptosis. MTT assay demonstrated that complexes 1 and 2 exhibited growth inhibition abilities on the three human cancer cell lines evaluated, and that complex 2 exhibited relatively better cytotoxic activities than complex 1 on the human lung cancer cell line A549. For this reason, complex 2 and the human lung cancer cell line A549 were employed in the subsequent apoptosis and western blot analyses. To determine whether the proliferation inhibition induced by complex 2 on A549 cells was attributed to the induction of apoptosis, Annexin V/PI staining and flow cytometry were applied to quantify the percentage of apoptosis. As shown in Fig. 3, the number of apoptotic A549 cells increased in a dose-dependent manner following incubation with 5, 10 and $15 \mu \mathrm{mol} / 1$ complex 2 for $48 \mathrm{~h}(\mathrm{P}<0.05)$.

Caspase 3, Bax and Bcl-2 protein expression. As previously reported, caspase 3 and Bcl-2 family proteins are key regulators of the apoptotic pathway. When caspase 3 and Bax expression is high, the cells proceed into apoptosis, while when Bcl-2 is produced in excess, cells are protected from apoptosis $(24,25)$. In the present study, western blotting was applied to detect the protein expression of caspase 3, Bax and Bcl-2 in the human lung cancer cell line A549 treated with different concentrations of complex 2 for $48 \mathrm{~h}$. The results revealed that caspase 3 and Bax protein expression significantly increased, while Bcl-2 protein expression was remarkably downregulated upon incubation with $5 \mu \mathrm{mol} / 1$ complex 2 for $48 \mathrm{~h}$ (Fig. 4). These results suggested that the possible mechanism of complex 2 responsible for its ability to induce A549 cell apoptosis may be associated with its ability to increase the expression of caspase 3 and Bax, and to decrease the expression of Bcl-2. These results may improve the understanding of the pharmacological mechanisms of novel $\mathrm{Ln}(\mathrm{III})$ complexes in cancer treatment.

In summary, two isostructural Ln(III) complexes with isonicotinohydrazone ligand have been isolated and characterized by elemental analyses, IR spectra and single-crystal XRD analyses in the present study. The results indicate that the two complexes exert considerable cytotoxic activity against three cancer cell lines (human lung cancer cell line A549, and human gastric cancer cell lines BGC823 and SGC7901), and that the $\mathrm{IC}_{50}$ values of complexes 1 and 2 are lower than that of the ligand. Annexin V/PI staining and western blotting further suggested that $\mathrm{Ln}$ (III) complexes can induce apoptosis in A549 cells. Those findings may potentially be useful for biomedical applications of novel Ln(III) complexes, particularly in the human cancer therapeutic field.

\section{Acknowledgements}

The present study was supported in part by the National Natural Science Foundation of China (grant nos. 81201908 
and 21404033), Fund of the Natural Science Foundation of Jiangsu (grant no. BK20141122), and Development Fund of Clinical Science and Technology of Jiangsu University (grant no. JLY20140065).

\section{References}

1. Tsuchida E and Oyaizu K: Oxovanadium (III-V) mononuclear complexes and their linear assemblies bearing tetradentate Schiff base ligands: Structure and reactivity as multielectron redox catalysts. Coord Chem Rev 237: 213-228, 2003.

2. Sherrington DC: Utilisation of homogeneous and supported chiral metal (salen) complexes in asymmetric catalysis. Chem Soc Rev 28: 85-93, 1999.

3. Shongwe MS, Al-Rahbi SH, Al-Azani MA, Al-Muharbi AA, Al-Mjeni F, Matoga D, Gismelseed A, Al-Omari IA, Yousif A, Adams H, et al: Coordination versatility of tridentate pyridyl aroylhydrazones towards iron: Tracking down the elusive aroylhydrazono-based ferric spin-crossover molecular materials. Dalton Trans 41: 2500-2514, 2012.

4. Krishnamoorthy P, Sathyadevi P, Senthilkumar K, et al: Copper (I) hydrazone complexes: Synthesis, structure, DNA binding, radical scavenging and computational studies. Inorg Chem Commun 14: 1318-1322, 2011.

5. Ni WX,Li M,Zhan SZ, Hou JZ and Li D: In situ immobilization of metalloligands: A synthetic route to homometallic mixed-valence coordination polymers. Inorg Chem 48: 1433-1441, 2009.

6. Tamasi G, Chiasserini L, Savini L, Sega A and Cini R: Structural study of ribonucleotide reductase inhibitor hydrazones. Synthesis and X-ray diffraction analysis of a copper (II)-benzoylpyridine-2-quinolinyl hydrazone complex. J Inorg Biochem 99: 1347-1359, 2005.

7. Song YM, Li WJ and Yang ML: Study on synthesis, characterization and antitumor activity of rare earth metal complexes with all trans retinoic acid and arginine acid. Chinese J Inorg Chem 30: 1087-1096, 2014

8. Bernhardt PV, Chin P, Sharpe PC, Wang JY and Richardson DR: Novel diaroylhydrazine ligands as iron chelators: Coordination chemistry and biological activity. J Biol Inorg Chem 10: 761-777, 2005.

9. Kalinowski DS, Sharpe PC, Bernhardt PV and Richardson DR: Structure-activity relationships of novel iron chelators for the treatment of iron overload disease: The methyl pyrazinylketone isonicotinoyl hydrazone series. J Med Chem 51: 331-344, 2008.

10. Xie QF, Gao PZ and Chen YM: Synthesis, crystal structure and anti-tumor activity in vitro of a hydrazone Schiff base and Its Cd(II) complex. Chinese J Inorg Chem 30: 2382-2388, 2014.
11. Sridhar SK, Saravanan M and Ramesh A: Synthesis and antibacterial screening of hydrazones, Schiff and Mannich bases of isatin derivatives. Eur J Med Chem 36: 615-625, 2001.

12. Banerjee S, Ray A, Sen S, et al: Pseudohalide-induced structural variations in hydrazone-based metal complexes: Syntheses, electrochemical studies and structural aspects. Inorganica Chim Acta 361: 2692-2700, 2008

13. Albrecht M, Osetska $\mathrm{O}$ and Fröhlich R: 2-[(8-Hydroxyquinolinyl) methylene]hydrazinecarboxamide: Expanding the coordination sphere of 8-hydroxyquinoline for coordination of rare-earth metal(III) ions. Dalton Trans 3757-3762, 2005.

14. Parker D, Dickins RS, Puschmann H, Crossland C and Howard JA: Being excited by lanthanide coordination complexes: Aqua species, chirality, excited-state chemistry, and exchange dynamics. Chem Rev 102: 1977-2010, 2002.

15. Hunter RB and Walker W: Anticoagulant action of neodymium 3-sulpho-isonicotinate. Nature 178: 47, 1956.

16. Kramsch DM, Aspen AJ and Rozler LJ: Atherosclerosis: Prevention by agents not affecting abnormal levels of blood lipids. Science 213: 1511-1512, 1981.

17. Hodnett EM and Dunn WJ III: Cobalt derivatives of Schiff bases of aliphatic amines as antitumor agents. J Med Chem 15: 339, 1972.

18. Hodnett EM and Mooney PD: Antitumor activities of some Schiff bases. J Med Chem 13: 786, 1970.

19. Wang Y and Yang ZY: Synthesis, characterization and DNA-binding properties of three $3 \mathrm{~d}$ transition metal complexes of the Schiff base derived from diethenetriamine with PMBP. Transit Metal Chem 30: 902-906, 2005.

20. Hao ZY, Liu QW. Xu J, Jia L and Li SB: Synthesis, characterization, antioxidant, activities and DNA-binding studies of (E)-N'-[1-(pyridin-2-yl)ethylidene]isonicotinohydrazide and its $\operatorname{Pr}(\mathrm{III})$ and $\mathrm{Nd}(\mathrm{III})$ complexes. Chem Pharm Bull (Tokyo) 58: 1306-1312, 2010

21. Sheldrick GM: SADABS, program for empirical absorption correction of area detector data. University of Göttingen, Germany. 1996.

22. Sheldrick GM: SHELX-97, program for the solution and refinement of crystal structures. University of Göttingen, Germany. 1997.

23. Cui Z, Li Y, Ling Y, Huang J, Cui J, Wang R and Yang X: New class of potent antitumor acylhydrazone derivatives containing furan. Eur J Med Chem 45: 5576-5584, 2010.

24. May P and May E: Twenty years of p53 research: Structural and functional aspects of the p53 protein. Oncogene 18: 7621-7636, 1999.

25. Cory S and Adams JM: The Bcl2 family: Regulators of the cellular life-or-death switch. Nat Rev Cancer 2: 647-656, 2002. 